\title{
Study on the dynamic numerical analysis method for the settlement of flexible pavement
}

The Mining-Geology-Petroleum Engineering Bulletin UDC: 624 DOI: $10.17794 / \operatorname{rgn} .2019 .4 .8$ Preliminary communication

\author{
Xiao-yu Xu'; Chao Liu' ${ }^{1,2}$; Chao Zhu'; Zhen-yuan Lv ${ }^{2}$ \\ ${ }^{\prime}$ School of Science, Xi'an University of Architecture and Technology, Xi'an, China \\ ${ }^{2}$ School of Civil Engineering, Xi'an University of Architecture and Technology, Xi'an, China
}

\begin{abstract}
In view of the problems of a single parameter of rock and soil materials, unclear boundary simulation and a simplified dynamic load in the current calculation of pavement settlement, the stochastic finite element-infinite element coupling method was adopted in this study to simulate the roadbed of rock and soil, with a dynamic response analysis and a flexible pavement settlement calculation of roadbed were carried out under stochastic dynamic load. Discrete methods and dynamic stochastic finite element formulas for rock and soil random fields were particularly dealt with in this study. The results show that the method to stimulate roadbed is true with high calculation accuracy and strong engineering guiding significance. The displacement of flexible ground at any depth can be obtained by calculating the settlement of flexible pavement with the aid of the Matlab computer program.
\end{abstract}

Keywords

dynamic analysis, flexible pavement, geotechnical random field, settlement calculation, stochastic finite element

\section{Introduction}

At present, when the pavement settlement in geotechnical engineering is calculated, the load is converted into static load, and the geotechnical characteristics are regarded as the deterministic factors to be simplified. In fact, a large part of the load on the rock and soil is dynamic load (Wang et al., 2016). For example, an automobile is running on the roadbed at a certain speed. Based on experimental data, the characteristics of rock and soil are random with a boundary infinite element (Chen et al., 1993; Hao et al., 2001; Cascetta et al., 2016; Liu et al., 2018). The analysis of dynamic randomness, which exists in any structure, is a task that must be studied now. The grounding shape of a vehicle load is simplified as a rectangle and the flexible pavement is regarded as a multi-layer elastic half-space in some studies (Yan 1998; Li 2001). There is an abundance of literature about the influence of factors such as moving speed and damping on the settlement of the pavement foundation. However, most of them are analyzed by finite element analysis (Ghiocel and Ghanem 2002). In this study, the settlement of flexible pavement was analyzed using the stochastic finite element-infinite element coupling method. The dynamic numerical analysis method for settlement of flexible pavement was implemented.

Corresponding author: Chao Liu

chaoliu@xauat.edu.cn

\section{Discrete method of geotechnical random field}

Foundation settlement and reliability in geotechnical engineering are mainly affected by the performance parameters of dielectric materials, boundary conditions and external loads. These factors are uncertain in a spatial location. In the numerical analysis of geotechnical engineering, the foundation should be considered as a function of a random field, and both the stress field and the displacement field have the characteristics of the random field. The average characteristic of the soil space within a certain range is determined by the geotechnical characteristics (Hu et al., 2018; He et al., 2018), so it is more suitable for the random field with a local average discrete synthesis method. In practical engineering, the material parameters of foundation soil have obvious characteristics of spatial variability and boundary infinite element, so the coupling model of a stochastic finite element and infinite element was used in the roadbed in this study. The roadbed central plane adopted a stochastic finite element method while the side and the bottom of the finite element adopted an infinite element method. The three-dimensional local average is more comprehensive and the most suitable for the actual situation. The local average method of a three-dimensional irregular element is adopted and the infinite element is a nonisoparametric element, which makes the analysis results closer to the actual project. In this study, $\alpha(x, y, z)$ is as- 
sumed to be a three-dimensional continuous homogeneous random field, whose mean value is $\mathrm{m}$, variance is $\sigma^{2}$, e is element, and the local homogeneous random field on element e is:

$$
\alpha_{e}=\frac{1}{V_{e}} \int_{\Omega e} \alpha(x, y, z) d x d y d z
$$

Where:

$V_{e}$ - volume of element e,

$\Omega_{e}-$ quadrilateral region occupied by unit e,

$(x, y, z)$ - value of any point of the element in global coordinate.

Then, the mean of $\alpha(x, y, z)$ is written as:

$$
E\left(\alpha_{e}\right)=E\left(\frac{1}{V_{e}} \int_{\Omega e} \alpha(x, y, z) d x d y d z\right)=m
$$

The covariance of homogeneous random field at any two nodes $\alpha_{e 1}$ and $\alpha_{e 2}$ is:

$$
\operatorname{cov}\left(\alpha_{e 1}, \alpha_{e 2}\right)=\frac{\sigma^{2}}{V_{e 1} V_{e 2}} \int_{\Omega e} \int_{\Omega e} \rho\left(x_{1}-x_{2}, y_{1}-y_{2}, z_{1}-z_{2}\right) d x_{1} d x_{2} d y_{1} d y_{2} d z_{1} d z_{2}
$$

Where:

$\rho\left(x_{1}-x_{2}, y_{1}-y_{2}, z_{1}-z_{2}\right)-$ standard correlation function for three-dimensional random field,

$V_{e l}$ - volume of element $\mathrm{e}_{1}$,

$V_{e 2}$-volume of element $\mathrm{e}_{2}$,

$\Omega_{e}$ - quadrilateral region occupied by unit e.

$$
\operatorname{cov}\left(\alpha_{e 1}, \alpha_{e 2}\right)=\frac{\sigma^{2}}{V_{e 1} V_{e 2}^{\prime}} \int_{-1}^{1} \int_{-1}^{1} \int_{-1}^{1} \int_{-1}^{1} \int_{-1}^{1} \int_{-1}^{1} \rho(r, s, t)\left|J_{1}\right|\left|J_{2}\right| d \xi_{1} d \xi_{2} d \eta_{1} d \eta_{2} d \zeta_{1} d \zeta_{2}
$$

Where:

$|J|$ - Jacobi matrix determinant,

$\left(x_{i}, y_{i}, z_{i}\right)$ - node coordinate value of element e,

$(\xi, \eta, \zeta)$ - local coordinate value of any point, and these are the parameters specified in the finite element method, $\rho(r, s, t)$ - a related standard function.

$$
\left\{\begin{array}{l}
r=\sum_{i=1}^{8}\left(N_{1 i} x_{1 i}-N_{2 i} x_{2 i}\right) \\
s=\sum_{i=1}^{8}\left(N_{1 i} y_{1 i}-N_{2 i} y_{2 i}\right) \\
t=\sum_{i=1}^{8}\left(N_{1 i} z_{1 i}-N_{2 i} z_{2 i}\right)
\end{array}\right.
$$

Where:

$N_{i}$ - shape function of the space eight-node finite element and infinite element selected.

Substituting Equation 5 into Equation 4, Equation 4 can be written as:

$$
\begin{aligned}
& \operatorname{cov}\left(\alpha_{e 1}, \alpha_{e 2}\right)=\frac{\sigma_{s}^{2}}{V_{e} V_{e}^{\prime}} \sum_{i=1}^{8} \sum_{i=1}^{8} \sum_{i=1}^{8} \sum_{i=1}^{8} \sum_{i=1}^{8} \sum_{i=1}^{8} H_{i} H_{j} H_{k} H_{p} H_{q} H_{r}\left|J\left(\xi_{i}, \eta_{j}, \zeta_{k}\right)\right|\left|J^{\prime}\left(\xi_{p}, \eta_{q}^{\prime}, \zeta_{R}\right)\right| \cdot \\
& \cdot \rho\left(\sum_{m=1}^{8}\left\{N_{m}\left(\xi_{i}, \eta_{j}, \zeta_{k}\right) x_{m}-N_{m}^{\prime}\left(\xi_{p}, \eta_{q}^{\prime}, \zeta_{R}\right) x_{m}^{\prime}\right\} \mid,\right. \\
& \left.\left|\sum_{m=1}^{8}\left\{N_{m}\left(\xi_{i}, \eta_{j}, \zeta_{j}\right) y_{m}-N_{m}^{\prime}\left(\xi_{p}, \eta_{p}^{\prime}, \zeta_{p}\right) y_{m}^{\prime}\right\}\right|,\left|\sum_{m=1}^{8}\left\{N_{m}\left(\xi_{i}, \eta_{j}, \zeta_{k}\right) z_{m}-N_{m}^{\prime}\left(\xi_{p}, \eta_{q}^{\prime}, \zeta_{R}\right) z_{m}^{\prime}\right\}\right|\right)
\end{aligned}
$$

Where:

$i, j, k, p, q, r-$ the number of the integration point,

$\left(\xi_{i}, \eta_{j}, \zeta_{k}\right)$ - local coordinate value of the integration point of element e,

$\left(\xi_{p}, \eta_{q}, \zeta_{r}\right)$ - local coordinate value of the integration point of element e', $H_{i}, H_{j}, H_{k}, H_{p}, H_{q}, H_{r}$ - the weighting coefficients. 
Equation 6 is obtained using the Gaussian-Legendre numerical integration method, which is also used by another researcher (Li et al., 2016).

As shown above, the element mesh was divided into $n_{1}$ finite elements and $n_{2}$ infinite elements, totaling $N=n_{1}+n_{2}$. The random field actually was discretized into $\mathrm{N}$ random variables so that the random finite element dynamic analysis can be carried out.

\section{Analysis of dynamic stochastic finite element formulation}

The element stiffness matrix was used to characterize the relationship between the force and deformation of the element body, which was analyzed in the first part. Besides, the perturbation dynamic formulation was discussed in the second part.

\subsection{Analysis of element stiffness matrix}

From the Hamilton variation principle of elastokinetics (Cai et al., 2016; Liu 2016), the basic equations of dynamic problems of the elastic system can be obtained:

$$
[M]\{\ddot{U}\}+[C]\{\dot{U}\}+[K]\{U\}=\{F(t)\}
$$

Where:

$M$ - mass matrix,

$C$ - damping matrix,

$K$-stiffness matrix,

$U$ - nodal displacement (m),

$\dot{U}$ - nodal speed $(\mathrm{m} / \mathrm{s})$,

$\ddot{U}$ - nodal acceleration $\left(\mathrm{m} / \mathrm{s}^{2}\right)$,

$F-\operatorname{nodal} \operatorname{load}(\mathrm{N})$.

In order to perform dynamic analysis on stochastic finite elements, parameter perturbations were performed on five random variables $M, C, K, U$ and $F$.

$K^{e}$ is integrated by the element stiffness matrix and can be expressed in the conventional space problem finite element as:

$$
K^{e}=\iiint B^{T} D B d x d y d z
$$

The element in the strain matrix $B$ is constant which isn't considered in a random analysis. The elastic matrix $D$ is related to the properties of the dielectric material and can be analyzed by random perturbation to reflect the random characteristics of the material. $K^{e}$ is affected by the elastic matrix $D$, and $D$ can be obtained by perturbation analysis of the material parameters. Let the mechanical parameters of the $i_{\text {th }}$ element be $E_{i}$ and $\mu_{i}$ that are random variables and can be expressed as:

$$
\left\{\begin{array}{l}
E_{i}=E^{0}\left(1+a \xi_{i}+b \xi_{i}^{2}\right) \\
\mu_{i}=\mu^{0}\left(1+c \xi_{i}+d \xi_{i}^{2}\right)
\end{array}\right.
$$

Where:

$E_{i}$ - the elastic modulus of $\mathrm{i}_{\text {th }}$ element $(\mathrm{MPa})$,

$\mu_{i}$ - the Poisson's ratio of $i_{\text {th }}$ element,

$E^{0}, \mu^{0}$ - definition value,

$a, b, c, d$ - variable coefficients,

$\xi_{i}$ - a small variable of random disturbance and its mean value is $\mathrm{E}\left(\xi_{i}\right)=0$.

Variance is obtained by $\mathrm{D}\left(\xi_{i}\right)=\operatorname{Var}\left(\xi_{i}\right)$. Substituting Equation 9 into the expression of $D$ and carrying out Taylor series expansion on $\xi_{i}$, we can take the quadratic term as:

$$
D=D^{0}+D^{1} \xi_{i}+D^{2} \xi_{i}^{2}
$$

Where:

$D^{0}$ - the elastic matrix of the conventional finite element,

$D^{l}, D^{2}$ - definition values which are only related to $E^{0}, \mu^{0}$. 
The element stiffness is obtained by combining Equation 8 and Equation 10:

$K_{i}^{e}=K_{i}^{0}+K_{i}^{1} \xi_{i}+K_{i}^{2} \xi_{i}^{2}(i=1,2 \cdots N)$

Where:

$\left\{\begin{array}{l}K_{i}^{0}=\iiint B^{T} D^{0} B d v \\ K_{i}^{1}=\iiint B^{T} D^{1} B d v \\ K_{i}^{2}=\iiint B^{T} D^{2} B d v\end{array}\right.$

Where:

$K_{i}^{0}$ - stiffness matrix of conventional finite element,

$K_{i}^{1}, K_{i}^{2}$ - the perturbing terms of the random variables.

Based on Equation 12, the element stiffness matrix of spatial random finite element and infinite element can be obtained. With the element stiffness matrix, the total stiffness matrix can be obtained by integration:

$$
K=K^{0}+\sum_{i=1}^{N} K_{i}^{1} \xi_{i}+\sum_{i=1}^{N} K_{i}^{2} \xi_{i}^{2}(i=1,2 \cdots, N)\left(N=n_{1}+n_{2}\right)
$$

Where $K^{0}$ is integrated by $\mathrm{n}_{1} K_{i}^{l}$ and $\mathrm{n}_{2} K_{i}^{2}, K_{i}^{l}, K_{i}^{2}$ are determined by the element type, and $\mathrm{n}_{1}, \mathrm{n}_{2}$ are the numbers of foundation finite elements and infinite elements, respectively. The element mass matrix is $M^{e}$, which can be expressed in the finite element of conventional space problem as:

$$
M^{e}=\int_{V} \rho[N]^{T}[N] d V
$$

Where:

$V$ - element domain,

$N$ - the shape function,

$[N]^{T}$ - the transpose of the shape function.

The density $\rho$ of each element is different and is a random variable, which can be calculated by perturbation:

$$
\rho=\rho_{0}\left(1+e \xi_{i}+\xi_{i}^{2}\right)
$$

Where:

$\rho_{0}-$ material density $\left(\mathrm{kg} / \mathrm{m}^{3}\right)$.

Then the element mass matrix:

$M^{e}=\int_{V} \rho_{0}\left(1+e \xi_{i}+\xi_{i}^{2}\right)[N]^{T}[N] d V=\int_{V} \rho_{0}[N]^{T}[N] d V\left(1+e \xi_{i}+\xi_{i}^{2}\right)=M_{i}^{0}+M_{i}^{1} \xi_{i}+M_{i}^{2} \xi_{i}^{2}$

With the element stiffness matrix, the total mass matrix can be integrated:

$$
M=M^{0}+\sum_{i=1}^{N} M_{i}^{1} \xi_{i}+\sum_{i=1}^{N} M_{i}^{2} \xi_{i}^{2}(i=1,2 \cdots, N)\left(N=n_{1}+n_{2}\right)
$$

Where:

$M^{0}$ - the total mass matrix of conventional finite element-infinite element integration,

$M_{i}^{1}, M_{i}^{2}$ - the variable coefficients when the total mass is integrated.

The inherent vibration mode of the system has orthogonality for $M$ and $K$. Therefore, the inherent vibration mode of the system also has orthogonality with respect to the damping matrix $C$ proportional to $M$ and $K$. Thus, the damping matrix is called proportional damping or vibration damping. In general, the proportional coefficient depends on the frequency coefficient. In practical analysis, it is very difficult to accurately determine the damping matrix. Usually, the damping matrix is simplified to a linear combination of $M$ and $K$, that is,

$$
C=\alpha M+\beta K
$$

Where:

$\alpha-$ a coefficient proportional to mass,

$\beta-$ a coefficient proportional to stiffness. 
This mode of vibration damping becomes Rayleigh damping. Then the damping is also a random variable and the element damping is:

$$
C^{e}=\alpha M^{e}+\beta K^{e}=\alpha\left(M_{i}^{0}+M_{i}^{1} \xi_{i}+M_{i}^{2} \xi_{i}^{2}\right)+\beta\left(K_{i}^{0}+K_{i}^{1} \xi_{i}+K_{i}^{2} \xi_{i}^{2}\right)=C_{i}^{0}+C_{i}^{1} \xi_{i}+C_{i}^{2} \xi_{i}^{2}
$$

Where:

$M^{0}$ - the total mass matrix of conventional finite element-infinite element integration,

$M_{i}^{1}, M_{i}^{2}$ - the variable coefficients when the total mass matrix is integrated,

$K^{0}$ - the total stiffness matrix of conventional finite element-infinite element integration,

$K_{i}^{1}, K_{i}^{2}$ - the variable coefficients when the total stiffness matrix is integrated,

$C^{0}$ - the total damping matrix of conventional finite element-infinite element integration,

$C_{i}^{1}, C_{i}^{2}$ - the variable coefficients when the total damping matrix is integrated.

With the element damping matrix, the total damping matrix can also be integrated:

$C=C^{0}+\sum_{i=1}^{N} C_{i}^{1} \xi_{i}+\sum_{i=1}^{N} C_{i}^{2} \xi_{i}^{2}(i=1,2 \cdots, N)\left(N=n_{1}+n_{2}\right)$

Where, $\alpha$ and $\beta$ can be determined by Equation 21:

$$
\left\{\begin{array}{l}
\alpha=\frac{2 \omega_{i} \omega_{j}\left(\lambda_{i} \omega_{j}-\lambda_{j} \omega_{i}\right)}{\omega_{i}^{2}-\omega_{j}^{2}} \\
\beta=\frac{2\left(\lambda_{j} \omega_{j}-\lambda_{i} \omega_{i}\right)}{\omega_{j}^{2}-\omega_{i}^{2}}
\end{array}\right.
$$

Where:

$\omega_{i}, \omega_{j}-$ the $\mathrm{i}_{\mathrm{th}}$ and $\mathrm{j}_{\mathrm{th}}$ inherent frequency respectively,

$\lambda_{i}, \lambda_{j}$-damping ratios for the $\mathrm{i}_{\mathrm{th}}$ and $\mathrm{j}_{\mathrm{th}}$ modes of vibration respectively.

\subsection{Analysis of perturbation dynamic formulation}

As can be seen from the above analysis, $U$ and $P$ are also parametric equations for random variables:

$$
U=U^{0}+\sum_{i=1}^{N} U_{i}^{1} \xi_{i}+\sum_{i=1}^{N} U_{i}^{2} \xi_{i}^{2}(i=1,2 \cdots, N)\left(N=n_{1}+n_{2}\right)
$$

Where:

$U_{i}^{1}, U_{i}^{2}$ - perturbation terms for $U^{0}$.

$$
P=P^{0}+\sum_{i=1}^{N} P_{i}^{1} \xi_{i}+\sum_{i=1}^{N} P_{i}^{2} \xi_{i}^{2}(i=1,2 \cdots, N)\left(N=n_{1}+n_{2}\right)
$$

Where:

$P_{i}^{1}, P_{i}^{2}$ - perturbation terms for $P^{0}$.

In fact, the load on the actual pavement foundation is a moving vehicle. Assume that the load moves uniformly along the $\mathrm{x}$-axis direction and the grounding shape of the vehicle load is simplified to be a rectangle, and the mathematical expression of the load is as follows:

$$
F(t)=\frac{P}{4 l_{1} l_{2}} H\left(l_{1}^{2}-x^{2}\right) H\left(l_{2}^{2}-y^{2}\right) f(t)
$$

Where:

$P-\operatorname{load}(\mathrm{N})$,

$H$ - Heaviside step function,

$f(t)$ - time-varying function of load intensity,

$l_{1}, l_{2}-$ the length and width of the simplified rectangle $(\mathrm{m})$, respectively.

Substituting $P$ into Equation 24 to get:

$$
F(t)=F^{0}+\sum_{i=1}^{N} F_{i}^{1} \xi_{i}+\sum_{i=1}^{N} F_{i}^{2} \xi_{i}^{2}(i=1,2 \cdots, N)\left(N=n_{1}+n_{2}\right)
$$

Where:

$F_{i}^{l}, F_{i}^{2}$ - correlated variable coefficients. 
When the load is earthquake load or wind load, the earthquake load is (Kumari and Sharma, 2019):

$$
F(t)=-[M] l \ddot{x}_{g}
$$

Where:

$l$ - element column vector,

$\ddot{x}_{\mathrm{g}}$ - earthquake ground motion acceleration.

The wind load is:

$$
F(t)=[A] W(t)
$$

Where $[A]=\left[\operatorname{diag}\left(A_{i}\right)\right], A_{i}$ is the product of the windward area and the body coefficient at the $\mathrm{i}_{\text {th }}$ particle, and $W(t)$ is a pulsation wind pressure.

Substituting the random variables $M, C, K, U$, and $F$ into the dynamic equation:

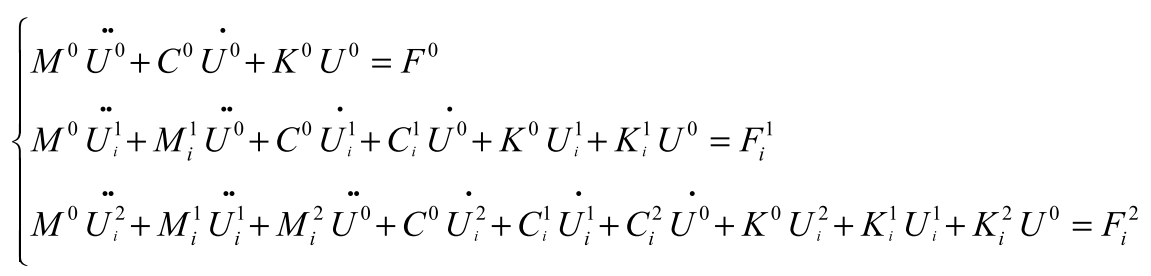

The spatially dynamic stochastic finite element formula is written as Equation 28. The elastic matrix involved in the calculation process is related to material properties, and thus the properties of the foundation material are considered. In addition, the random influence of loads and boundary conditions are also fully considered. The displacement value is further calculated. To carry out the reliability analysis of pavement settlement, it is necessary to statistically process the displacement and stress, and calculate the corresponding expected value and variance.

\section{Settlement calculation of flexible pavement}

Firstly, the stochastic finite element and infinite element mesh were divided on the pavement, and the coupling model of stochastic finite elements and infinite elements were established. Table 1 shows material characteristics of a multi-layer elastic half-space. The system acts on a moving cuboid car model $2 \mathrm{~m} \times 1 \mathrm{~m}$. The total load is $20 \mathrm{kN}$ and acts evenly on the four wheels, and the car model moves along a straight line at a speed of $10 \mathrm{~m} / \mathrm{s}$. The road surface is assumed to be completely flat. Elastic modulus, Poisson's ratio, and total load were taken as random variables. The element mesh was divided into four layers as shown in Figure 1, and the coefficient of variation for all parameters was taken as 0.2 .

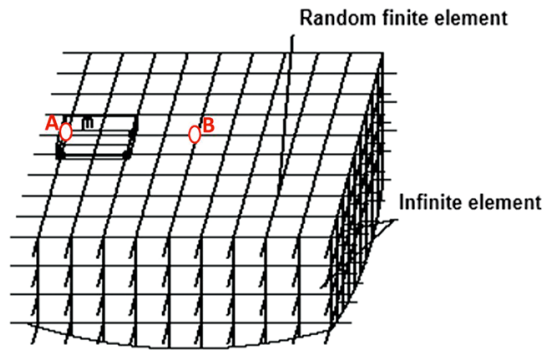

$\frac{\frac{\text { Load moving belt }}{\text { Surface layer }}}{\frac{\text { Basement layer }}{\text { Sub base }}}$

Figure 1: Calculation model of finite element

Table 1: Calculation parameters of materials at each layer

\begin{tabular}{|l|c|c|c|c|}
\hline & Surface layer & Basement layer & Sub base & Roadbed \\
\hline Elasticity modulus (MPa) & 2000 & 1200 & 400 & 50 \\
\hline Poisson ratio & 0.3 & 0.25 & 0.25 & 0.35 \\
\hline Density & 2500 & 2000 & 2000 & 1800 \\
\hline Damping matrix $\alpha$ & 0.4 & 0.4 & 0.4 & 0.4 \\
\hline Damping matrix $\beta$ & 0.01 & 0.01 & 0.01 & 0.01 \\
\hline
\end{tabular}

Deformation pattern of foundation surface is shown in Figure 2, Figure 3, and Figure 4 respectively, When $\mathrm{t}=0.1 \mathrm{~s}, \mathrm{t}=0.2 \mathrm{~s}$, and $\mathrm{t}=0.35 \mathrm{~s}$. 


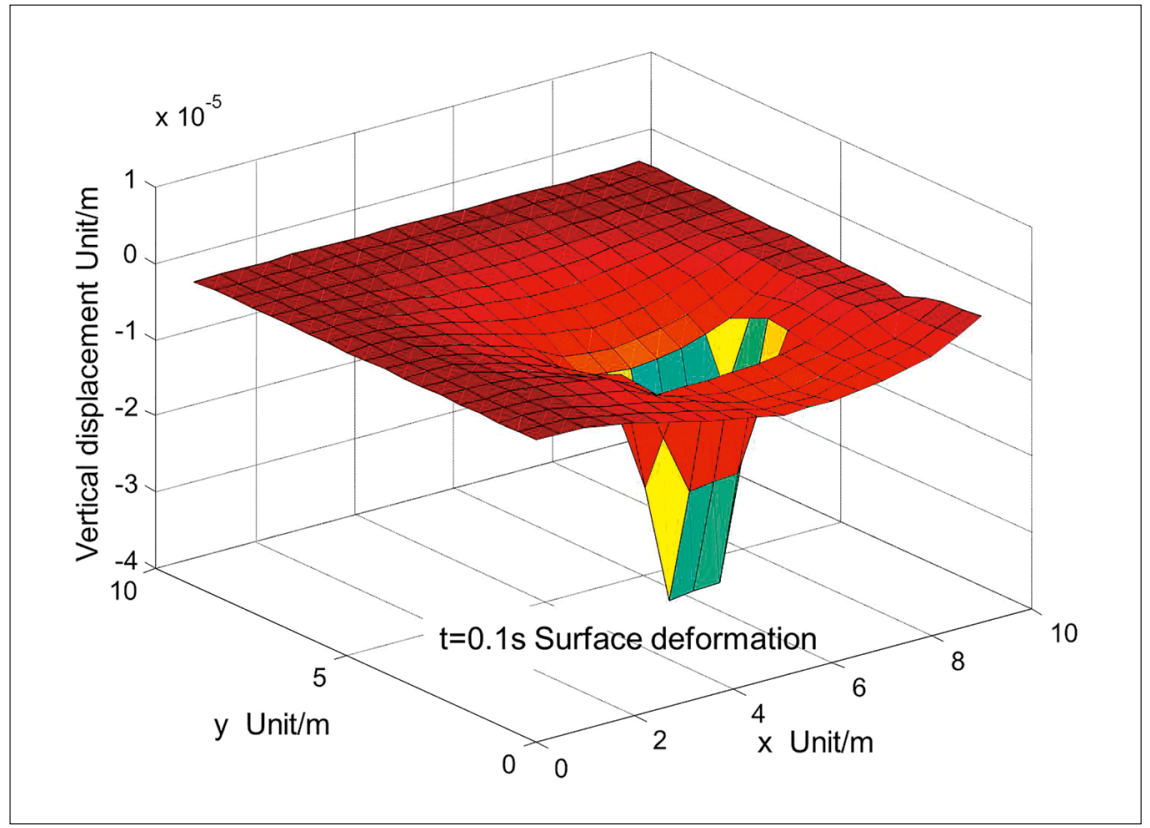

Figure 2: Settlement diagram of foundation surface when $t=0.1 \mathrm{~s}$

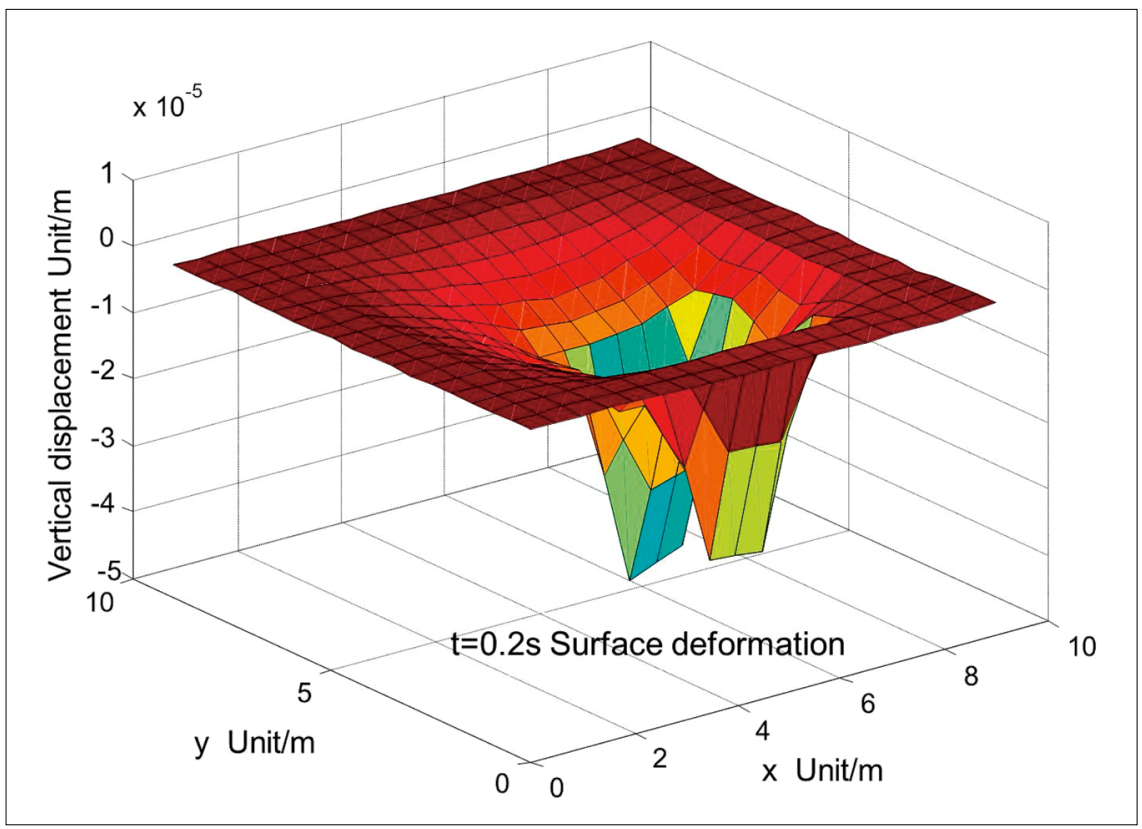

Figure 3: Settlement diagram of foundation surface when $t=0.2 \mathrm{~s}$

A random field was considered in the example above. With the movement of the vehicle model on the flexible pavement, the pavement settlement was calculated at $\mathrm{t}=0.1 \mathrm{~s}, 0.2 \mathrm{~s}$, and $0.35 \mathrm{~s}$, and the results showed that the pavement settlement changes unevenly with the dynamic load, which is closer to the actual settlement trend. Figure $\mathbf{5}$ shows the pavement settlement of the car model at different positions during the movement. The settlement rate at point A is faster in the initial time and gradually slows down over time (see Figure 5a), which is caused by the dynamic load gradually moving away from point A. This phenomenon is significantly different from the trend of settlement under a static load. On the contrary, as the trolley model moves closer to point B, the settlement rate at point B gradually becomes faster (see Figure 5b). The results show that the settlement of each position under dynamic load is different, which further demonstrates that the simulation of stochastic dynamic load using a vehicle load more accurately reflects the pavement settlement trend. The result of the example satisfies the normal settlement range, and this example can be used to simulate a situation when the flexible pavement has a dynamic load, which has a great application value in engineering. 


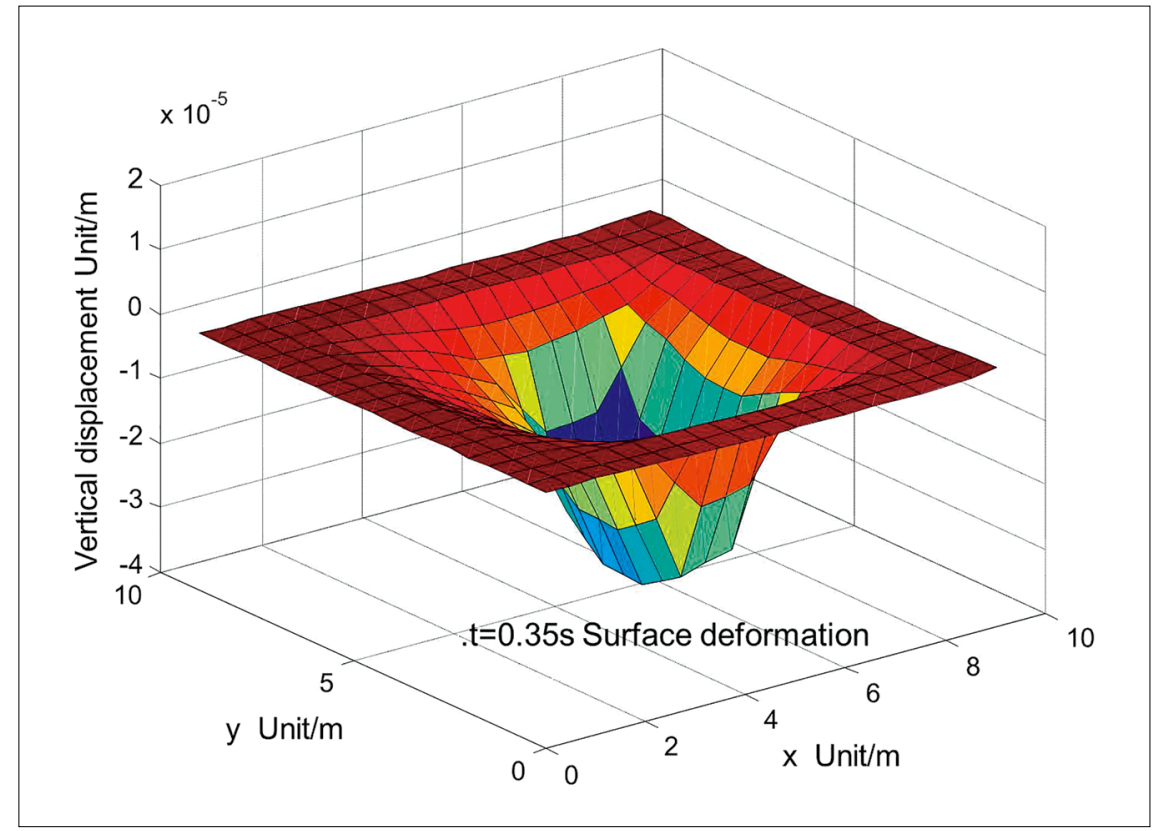

Figure 4: Settlement diagram of foundation surface when $t=0.35 \mathrm{~s}$

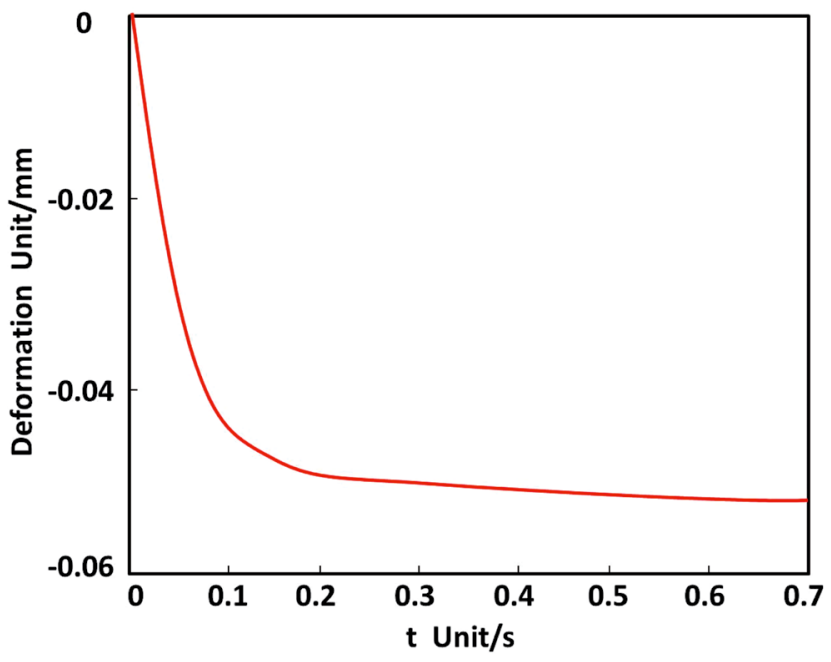

(a) Settlement of pavement at point $\mathrm{A}$

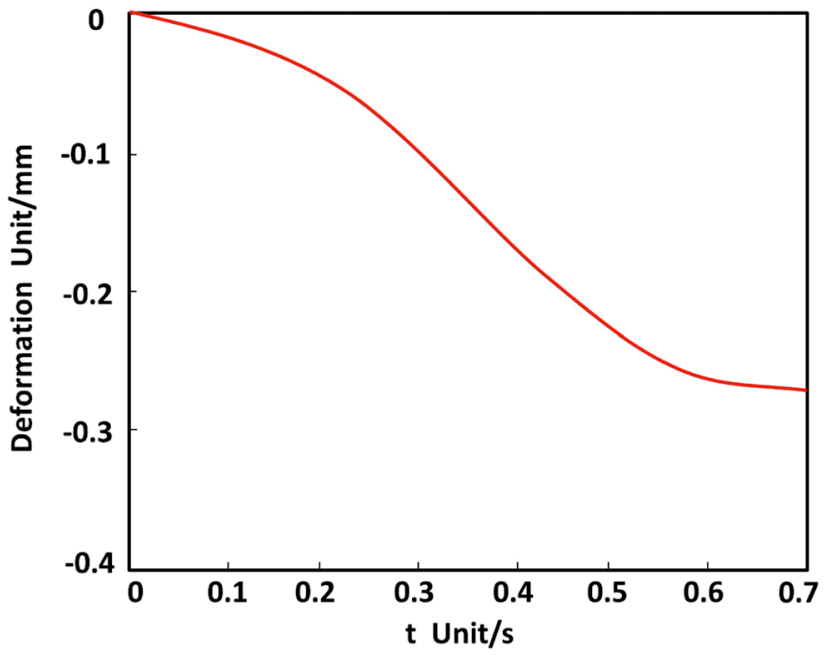

(b) Settlement of pavement at point B

Figure 5: Settlement of pavement at different locations during the movement of the trolley

\section{Conclusions}

It is feasible to use the coupling method of stochastic finite elements and infinite elements to simulate rock and soil of a roadbed. The actual settlement is more accurately reflected by the calculations of points A and B in the example. The method accurately reflects the characteristics of random discreteness of rock and soil and improves the accuracy of settlement calculation, which has good engineering guiding significance.

In this study, the actual dispersion is performed at a random field, and perturbation of the parameters is performed, which can more accurately perform the dynamic analysis of the stochastic finite element. Compared to the conventional way of replacing the dynamic load with a static load, the stochastic dynamic load method of simulating a vehicle load improves the accuracy of the numerical simulation.

The stochastic finite element method is used to solve the geotechnical engineering problem. However, the characteristics of rock and soil layer distribution make the trans-isotropic characteristic more obvious. In future studies, the combination of stochastic finite element-infinite element and trans-isotropic characteristic should be applied to the geotechnical engineering calculation so that the calculation result is more realistic and reliable. 


\section{Acknowledgements}

The authors would like to acknowledge the National Natural Science Foundation of China (Grant NO. 51878546), the Innovative Talent Promotion Plan of Shaanxi Province (Grant NO. 2018KJXX-056), the Science and Technology Coordination Innovation Project of Shaanxi Province(GrantNO. 2016KTZDSF04-02-01), the Key Research and Development Program of Shaanxi Province (Grant NO. 2018ZDCXL-SF-03-03-02), the Science and Technology Innovation Base of Shaanxi Province "Technology Innovation Service Platform for Solid Waste Resources and Energy Saving Wall Materials" (2017KTPT-19) and Key Technology Innovation Team Plan of Shaanxi Province (Grant NO. 2016KCT31) for their financial support.

\section{References}

Cai, Y.Q., Yu, Y.Z., Yuan, X.M., Wang, J. and Guo, L. (2016): Soil dynamics and geotechnical earthquake engineering. China Civil Engineering Journal, 49, 5, 9-30. DOI: 10.15951/j.tmgcxb.2016.05.002.

Cascetta, F., Musto, M., Rotondo, G. and Barbato, L. (2016): The influence of the filling percentage traffic on required ventilation thrust in road tunnel. International Journal of Heat and Technology, 34, (Special Issue 2), S451-S457. DOI: $10.18280 /$ ijht.34Sp0237.

Chen, Q. and Liu, X.B. (1993): Stochastic finite element method and its engineering application. Southwest Jiaotong University Press, Chengdu, 415 p.

Ghiocel, D.M. and Ghanem, R.G. (2002): Stochastic FiniteElement Analysis of Seismic Soil-Structure Interaction. Journal of Engineering, 128, 1, 82-98. https://doi.org/ 10.1061/(ASCE)0733-9399(2002)128:1(66).

Hao, Z.M. (2001): Finite Element Method and Reliability of Structures with Random Parameters. The Chinese academy of engineering physics, Chengdu, 140 p. https://c127 efc9a377ca478d1ab02839075b89.lib.xauat.edu.cn/.
He, Y.H., Jiang, C.W. and He, Y.C. (2018): Uncertainty study of natural convection in random porous media based on Monte-Carlo stochastic finite element method. Chinese Journal of Computational Mechanics, 35, 1, 12-51. DOI: 10. 7511 / jslx20161223002.

Hu, W.T. and Lv, L.Y. (2018): Reliability analysis of foundation settlement based on spectral stochastic finite element method. Engineering Construction, 27-32. DOI: 10.13402/ j.gcjs.2018.04.003.

Kumari, P. and Sharma, V.K. (2019): Dynamics of seismic waves in highly anisotropic triclinic media with intermediate monoclinic layer. Applied Mathematical Modelling, 71, 375-393. DOI:10.1016/j.apm.2019.02.029.

Li, D.Q., Xiao, T., Cao, Z.J., Zhou, C.B. and Fang, G.G. (2016): Slope risk assessment based on high efficiency stochastic finite element method. Rock and Soil Mechanics, 37, 7, 1994-2003. DOI: 10.16285/j.rsm.2016.07.021.

Li, Y. (2001): A Random FEM for Soil Engineering Reliability Analysis. Journal of Zhuzhou Institute of Technology, 15, 5, 66-68. https://cc0eb1c56d2d940cf2d0186445b0c858. lib.xauat.edu.cn/kns/detail/detail.aspx?FileName=ZZGX2 $00105022 \&$ DbName $=$ CJFQ2001.

Liu, C. (2016): Study on the coupling algorithm of finite element boundary element subdomain. Harbin Institute of Technology, Harbin, 89 p. https://68f0282b108d6b8325a6 f74af77abc40.lib.xauat.edu.cn.

Liu, C., Lv, Z.Y., Bai, G.L. and Yin Y.G. (2018): Experiment study on bond slip behavior between section steel and RAC in SRRC structures. Construction and Building Materials, 175, 104-114. https://doi.org/10.1016/j.conbuildmat.2018.04.120.

Wang, X.Z. and Wang, C.Q. (2016): Analysis of temperature stress in control of bridge construction. International Journal of Heat and Technology, 34, 4, 715-721. DOI: 10.18280/ijht.340423.

Yan, L.B. (1998): Finite element and infinite element method for structural analysis. Wuhan university of technology press, Wuhan, $175 \mathrm{p}$. 


\section{SAŽETAK}

\section{Izučavanje dinamičke numeričke analize kod postavljanja fleksibilnoga kolnika}

U slučaju problema jednoga parametra u karakterizaciji stijena i tala, kada je njihova granica nejasna, što ima utjecaja na simulaciju i izračun pojednostavljenoga opterećenja kod postavljanja kolnika, primijenjena je stohastička metoda konačnih elemenata. Njome su simulirane podloga prometnice, sastavljena od stijene i tla, te dinamički odgovor fleksibilnoga kolnika u slučajevima stohastičkoga, promjenjivoga opterećenja. Uporabljene su diskretne metode i jednadžbe dinamičko-stohastičkih konačnih elemenata, posebice za slučajna polja stijena i tala. Rezultat je pokazao kako je stimuliranje podine kolnika predviđeno s visokom preciznošću te može poslužiti kao vodilja u projektiranju kolnika. Uporabom paketa MATLAB pomaci tla mogu se proračunati na željenoj dubini ispod kolnika.

\section{Ključne riječi:}

dinamička analiza, fleksibilni kolnik, geotehničko slučajno polje, izračun podine, stohastički konačni elementi

\section{Authors contribution}

Xiao-yu Xu (Master student in Xi'an University of Architecture and Technology) adopted a stochastic finite elementinfinite element coupling method to simulate the roadbed of rock and soil and wrote the paper. Chao Liu (Ph.D, Professor in Xi'an University of Architecture and Technology) provided the data and guided the existing problems in the paper. Chao Zhu (Ph.D. candidate in Xi'an University of Architecture and Technology) calculated the pavement settlement. Zhen-yuan Lv (Master student in Xi'an University of Architecture and Technology) helped to revise the paper. 